\title{
Water-Energy-Food Nexus: A Coupled Simulation and Optimization Framework
}

\author{
Ali Karnib \\ Lebanese University, Hadath Campus, Baabda, Lebanon \\ Email:karnib.ali@gmail.com
}

How to cite this paper: Karnib, A. (2017) Water-Energy-Food Nexus: A Coupled Simulation and Optimization Framework. Journal of Geoscience and Environment Protection, 5, 84-98.

https://doi.org/10.4236/gep.2017.54008

Received: March 7, 2017

Accepted: April 22, 2017

Published: April 25, 2017

Copyright (c) 2017 by author and Scientific Research Publishing Inc. This work is licensed under the Creative Commons Attribution International License (CC BY 4.0).

http://creativecommons.org/licenses/by/4.0/

Open Access

\begin{abstract}
Water, Energy and Food (WEF) nexus systems are developed to model and analyze interactions across and between WEF sectors. WEF nexus simulation models permit evaluating the direct and indirect WEF quantitative interaction effects in response to change of technology and/or demand. Optimization models can help to find the optimal combinations of WEF nexus system policy options and parameters that lead to the best performance of the system. This paper describes a framework for integrating quantitative WEF nexus simulation model (the Q-Nexus Model) with an optimization tool, which will give policy makers the ability to compromise best policy options based on WEF nexus simulator. The developed method is then applied to the numerical experiment and the results are discussed. Lastly, the conclusions and further developments are presented.
\end{abstract}

\section{Keywords}

Water Energy Food Nexus, Simulation, Optimization, Sustainable Development

\section{Introduction}

Numerous water, energy and food nexus systems are developed to analyze interactions between WEF sectors with the purpose of managing vital resources in the context of various competing interests [1]-[11]. The use of mathematical modeling in planning WEF policies is well documented in literature [1] [7] [12]. In addition, the application of optimization approaches to real world problems to guide decision making has been recognized as a key research challenge [13] [14] [15].

The water, energy and food nexus interactions are complex and dynamic, and they directly and indirectly affect one another [1]. The term nexus is used to de- 
scribe these interactions and the nexus quantitative assessment models can help in mitigating their effects and in identifying trade-offs. The key property that should categorize any WEF nexus quantitative model is its ability to calculate the direct and indirect intersectoral quantities emerging from projected change of the WEF nexus components. This property must be considered as the basic condition to distinguish between quantitative-based nexus systems and any other resources integrated systems.

To better highlight the direct and indirect WEF interaction effects, Figure 1 shows an example of the total water input (the sum of the direct and all indirect water inputs) required for new additional food demand.

As shown in Figure 1, the effect of new additional demand for food generates within the nexus a need for inputs from water and energy resources; this is the direct impacts. But these water and energy outputs themselves generate once again a need for additional resources; these are the first measures of the indirect impacts, and so forth.

Evidently, the accurate analysis of WEF nexus systems necessitates evaluating the direct and indirect quantitative effects. Despite the utility of evaluating these effects, they have yet to be used in a decision making framework by applying optimization algorithms to seek optimal policies for WEF nexus systems management. Facilitating the use of WEF nexus simulation models with independently developed optimization software provides a powerful tool for decision makers. The Q-Nexus Model as a WEF nexus simulator has already been used to influence policy and planning [1] [16]. However, its use within a flexible optimization framework where model inputs can instead become decision variables and model outputs can be used in mathematical representations of resource management goals, has not yet been tested. A coupled simulation and optimization framework provides a tool in which stakeholders can define their own objectives and still benefit from the sophisticated modeling capabilities of the Q-Nexus Model simulator that permits assessing the direct and indirect intersectoral WEF quantities.

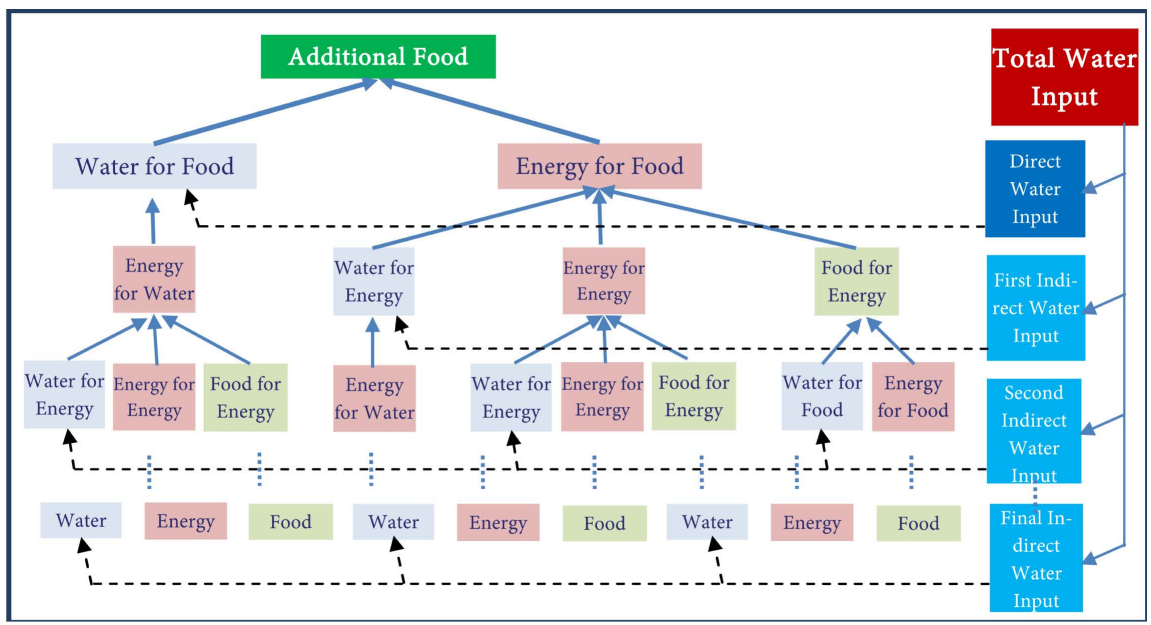

Figure 1. Direct and indirect water inputs for additional food demand. 
Two types of simulation could be performed using the Q-Nexus Model, the first type consists of analyzing scenarios related to variation of resources demand or reducing losses; the second type of simulation consists of analyzing scenarios of changing the technology by considering "High Efficient" and "Best Practice" technology alternatives. Moreover, the model permits to simulate different WEF intersectoral allocation policies and evaluate the performance of the system [1] [16]. Figure 2 presents the Q-Nexus Model and its input and output variables.

Our focus in this work is the applicability of optimization techniques to aid in WEF nexus decision making in terms of selection of best policy options using QNexus Model simulator outputs. A flexible simulation and optimization framework that can easily be used for various WEF planning or management objectives is proposed.

\section{Coupled Simulation and Optimization Framework for the WEF Nexus}

Coupling WEF nexus simulation and optimization techniques (S-O) will certainly lead to investigate valuable knowledge that the simulation model may yield. The motif is to explore instantaneously the great detail provided by simulation and the ability of optimization techniques to find optimal results. The application of optimization techniques will derive the greatest benefit from a simulation model, as a matter of fact; the optimization model can be used to execute the WEF nexus simulation many times, to determine the best input values to achieve desired system outputs. Important optimization questions that can be answered to inform the sustainable WEF planning by combining simulation and optimization techniques include:

- What combinations of WEF nexus system policy options and input parameters lead to the best and worst performance of the system?

- What are the best tradeoffs between multiple competing objectives?

Combining S-O techniques can provide answers to these crucial questions and key insights for policy makers.

A thoroughly study of classification and discussion on this approach is presented in [17]. In general, the idea is to couple the simulation and the optimiza-

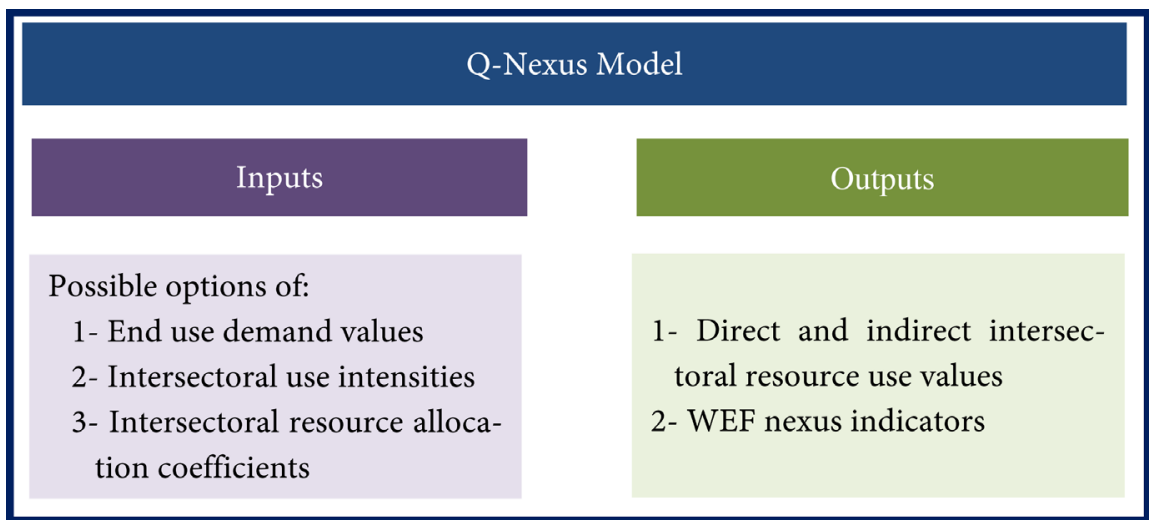

Figure 2. The input and output variables of the Q-Nexus Model. 
tion tools or approaches to build up a closed loop system. The coupled simulation and optimization approach has been applied in different fields to resolve optimization problems in the literature [13] [18] [19] [20] [21] [22]. From the literature we can observe that the coupled simulation and optimization approach is usually used for two objectives: decision making via optimization and performance evaluation via simulation. The approach is similar; however a specific model is necessary to resolve a specific problem. The objective functions of the optimization approach represent the WEF sectors planning and management goals. These objectives may include consideration of minimizing resource use and maximizing revenue.

One of the advantages of coupled simulation and optimization is the ability to define objective functions outside the simulation tool; that is, the objective functions rely only on output from the simulation model. Thus, any modeling input or output could be adapted as a decision variable or used within objective function and constraint evaluations, respectively.

Figure 3 presents the framework for coupling Q-Nexus Model with optimization tool showing the simulation model components and the cyclic flow of information throughout the optimization process. For example, the output of optimization tool serve as input to the simulation model; and after processed, the output of the simulation model will be used as the input for the optimization model at the start of the next iteration.

The optimization techniques treat the Q-Nexus Model as a black box, requiring only that each set of input values yields corresponding output values. This pairing of optimization with WEF nexus simulation model can be used beneficially anytime a WEF nexus system is being modeled and many combinations of input parameters are being considered.

Spreadsheet tools could be used as wrapper for the proposed framework where the simulation model and optimization tool could be implemented and

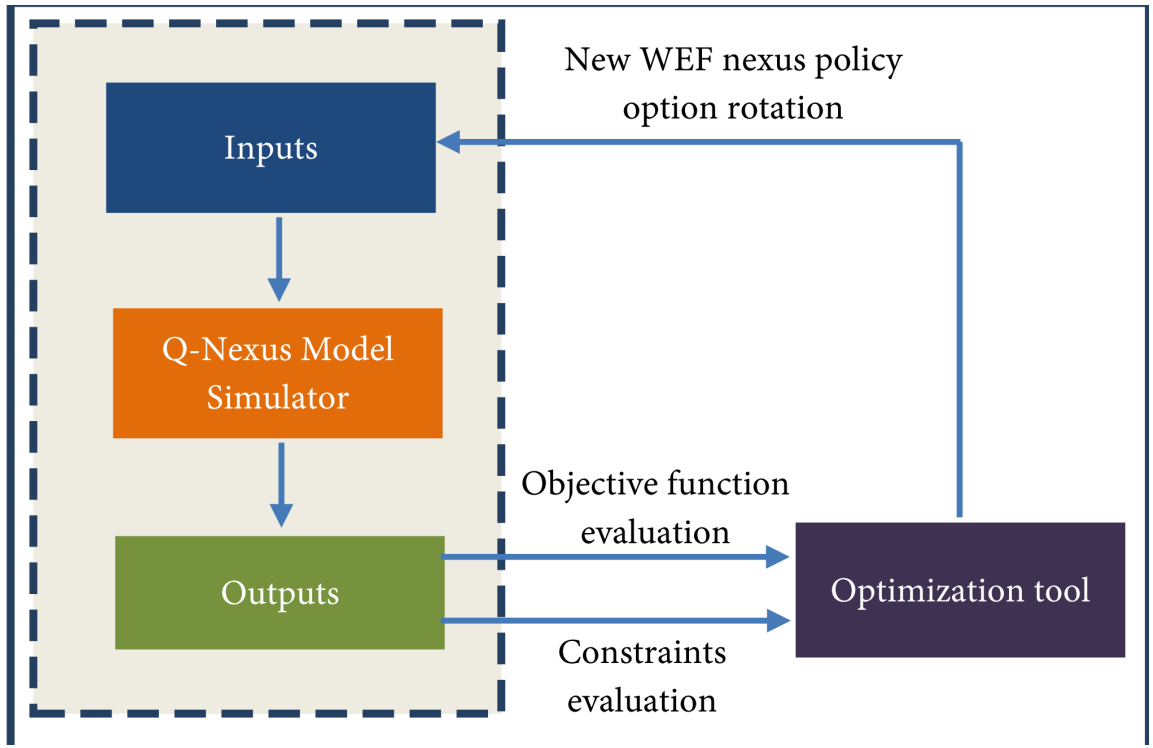

Figure 3. Framework for coupling Q-Nexus Model with optimization tool. 
easily operated. This allows policy maker to identify decision variables from the input parameters and specify outputs of the Q-Nexus Model needed for evaluation of the objective functions and constraints.

\section{Problem Formulation}

\subsection{Review of the WEF Nexus Model}

The Q-Nexus Model is built on the input-output theory and is being able to evaluate quantitatively both the direct and indirect intersectoral WEF quantities [1] [16]. The structure of the Q-Nexus Model is based on the quantitative balance of the WEF total quantities through two main conceptual elements: i) the intersectoral use quantities $(Z)$ and ii) the end use quantities $(y)$ which cover households, government and the rest of the economy demands, losses, accumulation and exports. The sum of these two components gives the total resources quantities $(x)$.

A set of inflows were identified to represent the WEF sectors, for example, surface water, groundwater, desalination, wastewater and drainage water reuse inflows covering the water sector, imported petroleum and all types of electricity including renewable energy, covering the energy sector, and irrigated cereals, irrigated roots and other food production items covering the area of food. These inflows are particularly identified for the Lebanese case study presented in [1], the organization of these elements could change to take into account diversification related to local, national and regional particularities.

A set of equations are developed in [1] [16] to mathematically shape the QNexus Model. In addition to the three variable elements $(Z),(y)$ and $(x)$, one of the key outcomes of the mathematical formulation of the model is the intersectoral technology matrix $(A)$. This matrix is one of the key variables of the model because it represents the identity of the nexus system and it is constructed as follows:

If we denote by:

$n$ : number of water resources inflows;

$m$ : number of energy resources inflows;

$h$ : number of food resources inflows;

$z_{i j}^{w}{ }^{w}$ : : the use of $i^{\text {th }}$ water resource inflow in the $j^{\text {th }}$ energy resource inflow;

$z_{i j}^{w^{-} f}$ : the use of $i^{\text {th }}$ water resource inflow in the $f^{\text {th }}$ food resource inflow;

$z_{i j}^{e}{ }^{e}$ : : the use of $I^{t h}$ energy resource inflow in the $f^{t h}$ water resource inflow;

$z_{i j}^{e}{ }^{e}$ : the use of $i^{\text {th }}$ energy resource inflow in the $f^{\text {th }}$ energy resource inflow;

$z_{i j}^{e}{ }^{e}$ : the use of $I^{t h}$ energy resource inflow in the $f^{\text {th }}$ food resource inflow;

$Z_{i j}^{f}{ }^{e}$ : the use of $i^{\text {th }}$ food resource inflow in the $f^{\text {th }}$ energy resource inflow;

$z_{i j}^{f-f}$ : the use of $i^{\text {th }}$ food resource inflow in the $f^{\text {th }}$ food resource inflow;

and $z_{j}^{w_{-} e}=\sum_{i=1}^{n} z_{i j}^{w_{-} e}$ the water use in the $f^{t h}$ energy inflow;

$z_{j}^{w_{-}} f=\sum_{i=1}^{n} z_{i j}^{w_{-} f}$ the water use in the $f^{\text {th }}$ food inflow;

$z_{j}^{e_{-} w}=\sum_{i=1}^{m} z_{i j}^{e_{-} w}$ the energy use in the $f^{\text {th }}$ water inflow; 
$z_{j}^{e_{-} f}=\sum_{i=1}^{m} z_{i j}^{e_{-} f}$ the energy use in the $f^{\text {th }}$ food inflow; $z_{j}^{f_{-}}{ }^{e}=\sum_{i=1}^{m} z_{i j}^{f_{-} e}$ the food use in the $f^{t h}$ energy inflow.

The WEF intersectoral use intensities $(t)$ are defined as follows:

$$
\begin{aligned}
& t_{j}^{w_{-} e}=\frac{z_{j}^{w_{-} e}}{x_{j}^{e}}, \\
& t_{j}^{w_{-} f}=\frac{z_{j}^{w_{-} f}}{x_{j}^{f}}, \\
& t_{j}^{e_{-} w}=\frac{z_{j}^{e_{-} w}}{x_{j}^{w}}, \\
& t_{j}^{e_{-} e}=\frac{z_{j}^{e_{-} e}}{x_{j}^{e}}, \\
& t_{j}^{e_{-} f}=\frac{z_{j}^{e_{-} f}}{x_{j}^{f}}, \\
& t_{j}^{f-e}=\frac{z_{j}^{f-e}}{x_{j}^{e}}, \\
& t_{j}^{f-f}=\frac{z_{j}^{f-f}}{x_{j}^{f}}
\end{aligned}
$$

where $x_{j}^{w}, x_{j}^{e}, x_{j}^{f}$ are the total use of the $f^{t h}$ water resource inflow, total use of the $j^{\text {th }}$ energy resource inflow and total use of the $f^{\text {th }}$ food resource inflow, respectively.

The WEF intersectoral allocation coefficients $(c)$ are defined as follows:

$$
\begin{aligned}
& C_{i j}^{w_{-} e}=\frac{z_{i j}^{w_{-} e}}{z_{j}^{w_{-} e}}, \\
& c_{i j}^{w_{-} f}=\frac{z_{i j}^{w_{-} f}}{z_{j}^{w_{-} f}}, \\
& C_{i j}^{e_{-} w}=\frac{z_{i j}^{e_{-} w}}{z_{j}^{e^{-} w}}, \\
& C_{i j}^{e_{-} e}=\frac{Z_{i j}^{e_{-} e}}{Z_{j}^{e_{-} e}}, \\
& C_{i j}^{e_{-} f}=\frac{z_{i j}^{e_{-} f}}{z_{j}^{e_{-} f}}, \\
& C_{i j}^{f-e}=\frac{Z_{i j}^{f-e}}{Z_{j}^{f-e}}, \\
& C_{i j}^{f-f}=\frac{Z_{i j}^{f-f}}{Z_{j}^{f-f}}
\end{aligned}
$$


The technology matrix $A$ was demonstrated in [16] as function of $(t)$ and $(c)$ as follows:

$$
A=\left[\begin{array}{ccc}
0 & C^{w_{-} e} \widehat{t^{w_{-} e}} & C^{w_{-} f} \widehat{t^{w_{-} f}} \\
C^{e_{-} w^{e_{-} w}} & C^{e_{-} e} \widehat{t^{e_{-} e}} & C^{e_{-} f} \widehat{t^{e_{-} f}} \\
0 & C^{f_{-} e} \widehat{t^{f_{-} e}} & C^{f_{-} f} \widehat{t^{f_{-} f}}
\end{array}\right]
$$

where

$\hat{t}$ is the diagonal matrix with the elements of the $t$ along the main diagonal.

The water for water and food for water relationships are considered quantitatively negligible, so they are set equal to zero in the above equation.

The total outputs $(x)$ caused by end use quantities $(y)$ are linked by the following equation [1]:

$$
x=(I-A)^{-1} y
$$

where $I$ is the identity matrix.

The changes in end use and the resulting changes in intersectoral quantities are linked by the following equation [1]:

$$
\Delta Z=A \widehat{\Delta x}
$$

$\widehat{\Delta x}$ is the diagonal matrix with the elements of the $\Delta x$ along the main diagonal.

\subsection{Objective Function and Constraints}

In quantitative-based WEF nexus system, several water and energy inflows are used in the production of the water, energy and food resources [1]. For example, the total water use in the electricity and food production can be originated from different water sources (i.e. surface water, groundwater, desalination ...); the allocation coefficients of water use are the proportion of the different water sources used to the total water use in a resource production. Moreover, the energy use to produce water differ according the type of water source, for example, the energy used to abstract surface water is usually less than the energy used to abstract groundwater or desalination.

Additional food quantities will generate within the WEF nexus system needs for total (direct and indirect) additional water and energy resources $\left(\Delta z_{i}^{w}\right.$ and $\left.\Delta z_{i}^{e}\right)$. In this study, we consider finding the best water and energy allocations in WEF sectors that optimize the performance of the WEF nexus system by minimizing the total cost of resources required to produce additional food quantities.

Hereafter, the objective function and constraints are presented.

The total additional intersectoral water use (direct and indirect) could be evaluated using the Q-Nexus Model simulator, where:

$$
\Delta z_{i}^{w}=\sum_{j=1}^{m} \Delta z_{i j}^{w_{-} e}+\sum_{j=1}^{h} \Delta z_{i j}^{w_{-} f}, i=1, \cdots, n .
$$

Similarly, the total additional intersectoral energy use (direct and indirect) could be evaluated using the Q-Nexus Model simulator, where:

$$
\Delta z_{i}^{e}=\sum_{j=1}^{n} \Delta z_{i j}^{e_{-} w}+\sum_{j=1}^{m} \Delta z_{i j}^{e_{-} e}+\sum_{j=1}^{h} \Delta z_{i j}^{e_{-} f}, i=1, \cdots, m .
$$


These simulation output values will serve as objective function for the optimization tool:

If the cost in US dollars per meter cube of water resource produced is denoted $\left(p_{i}^{w}\right)\left(\mathrm{USD} / \mathrm{m}^{3}\right)$, and the cost in US dollars per tons of oil equivalent of energy resource produced is denoted ( $p_{i}^{e}$ ) (USD/toe), the total cost could be evaluated as follows:

$$
\text { Cost }=\sum_{i=1}^{n} \Delta z_{i}^{w} p_{i}^{w}+\sum_{i=1}^{m} \Delta z_{i}^{e} p_{i}^{e} .
$$

The estimation of $\left(p_{i}^{w}\right)$ and $\left(p_{i}^{e}\right)$ will be discussed in Section 3.3.

The objective function: Minimum Cost

The decision variables are the water and energy allocations in WEF sectors: $c_{i j}^{w_{-} e}, c_{i j}^{w_{-} f}, C_{i j}^{e_{-} w}, C_{i j}^{e_{-} e}$ and $c_{i j}^{e_{-} f}$.

Subject to the following constraints:

$\sum_{j=1}^{m} c_{i j}^{w \_e}=1$ if the energy inflow $j$ is using water, 0 if not $(i=1, \cdots, n)$.

$\sum_{j=1}^{h} c_{i j}^{w_{-} f}=1$ if the food inflow $j$ is using water, 0 if not $(i=1, \cdots, n)$.

$\sum_{j=1}^{n} c_{i j}^{e_{-}-w}=1$ if the water inflow $j$ is using energy, 0 if not $(i=1, \cdots, m)$.

$\sum_{j=1}^{m} c_{i j}^{e^{e}}{ }^{-}=1$ if the energy inflow $j$ is using energy, 0 if not $(i=1, \cdots, m)$.

$\sum_{j=1}^{h} c_{i j}^{e-f}=1$ if the food inflow $j$ is using energy, 0 if not $(i=1, \cdots, m)$.

$$
\begin{gathered}
\sum_{j=1}^{m} \Delta z_{i j}^{w}{ }^{e}+\sum_{j=1}^{h} \Delta z_{i j}^{w_{-}} f \leq \Delta v_{i}^{w} \quad(i=1, \cdots, n) . \\
\sum_{j=1}^{n} \Delta z_{i j}^{e^{-}{ }^{w}}+\sum_{j=1}^{m} \Delta z_{i j}^{e} e^{-}+\sum_{j=1}^{h} \Delta z_{i j}^{e-f} \leq \Delta v_{i}^{e} \quad(i=1, \cdots, m)
\end{gathered}
$$

where $\Delta v_{i}^{w}$ and $\Delta v_{j}^{e}$ are the maximum envisaged additional capacities of the water and energy resources inflows $(i=1, \cdots, n$ and $j=1,2, \cdots, m)$.

\subsection{Estimation of the Cost of Additional Resources}

The S-O framework will be used to find the best water and energy resource allocations that minimize the total cost to produce the required additional water and energy resources.

The additional resource cost (in USD) covers building and operating a generating resource plants over an assumed financial life and duty cycle. Key inputs to calculating additional resource cost include construction costs, financing costs, and an assumed utilization rate for each plant type [23] (EIA 2016). The cost in US dollars per meter cube of water resource produced $\left(p_{i}^{w}\right)\left(\mathrm{USD} / \mathrm{m}^{3}\right)$ and the cost in US dollars per tons of oil equivalent of energy resource produced $\left(p_{i}^{e}\right)$ (USD/toe) are estimated based on a 30-year cost recovery period for various types of water supply and energy production options. It is important to mention that the cost parameters are generally combined with the capacity factors (EIA, 2016).

If we denote by:

$P_{i \max }^{w}$ : maximum cost per unit of water resource produced, $i=1, \cdots, n$, 
$P_{i \max }^{e}:$ maximum cost per unit of energy resource produced, $i=1, \cdots, m$,

$P_{i \min }^{w}$ : minimum cost per unit of water resource produced, $i=1, \cdots, n$,

$P_{i \min }^{e}$ : minimum cost per unit of energy resource produced, $i=1, \cdots, m$,

$S_{i \max }^{w}:$ maximum capacity of water production plant, $i=1, \cdots, n$,

$S_{i \max }^{e}:$ maximum capacity of energy production plant, $i=1, \cdots, m$,

$S_{i \min }^{w}$ : minimum capacity of water production plant, $i=1, \cdots, n$,

$S_{i \min }^{e}$ : minimum capacity of energy production plant, $i=1, \cdots, m$.

To take into account the capacity factors when estimating the costs per unit of resource produced, a gradual decline cost is assumed with increasing of water and energy plant sizes, starting from the estimated maximum costs per unit of resource $i$ produced $P_{i \max }^{w}$ and $P_{i \max }^{e}$ for $S_{i \min }^{w}$ and $S_{i \min }^{e}$ capacities of water and energy plants, until that is reached minimum costs per unit of resources produced $P_{i \min }^{w}$ and $P_{i \min }^{e}$ for plants with sizes greater than $S_{i \max }^{w}$ and $S_{i \max }^{e}$ as shown in Figure 4 and Figure 5.

If $\Delta z_{i}^{w}$ is the measure of the total additional intersectoral water use (direct and indirect) of a resource $i$, the water resource cost $\left(p_{i}^{w}\right)$ is calculated using the proposed method as follows:

$$
\begin{aligned}
& \text { If } \Delta z_{i}^{w}<S_{i \min }^{w} \text { then } p_{i}^{w}=P_{i \max }^{w} . \\
& \text { If } S_{i \min }^{w} \leq \Delta z_{i}^{w} \leq S_{i \max }^{w} \text { then } p_{i}^{w}=P_{i \min }^{w}+\left(S_{i \max }^{w}-\Delta z_{i}^{w}\right) \frac{P_{i \max }^{w}-P_{i \min }^{w}}{S_{i \max }^{w}-S_{i \min }^{w}} . \\
& \text { If } \Delta z_{i}^{w}>S_{i \max }^{w} \text { then } p_{i}^{w}=P_{i \min }^{w} .
\end{aligned}
$$

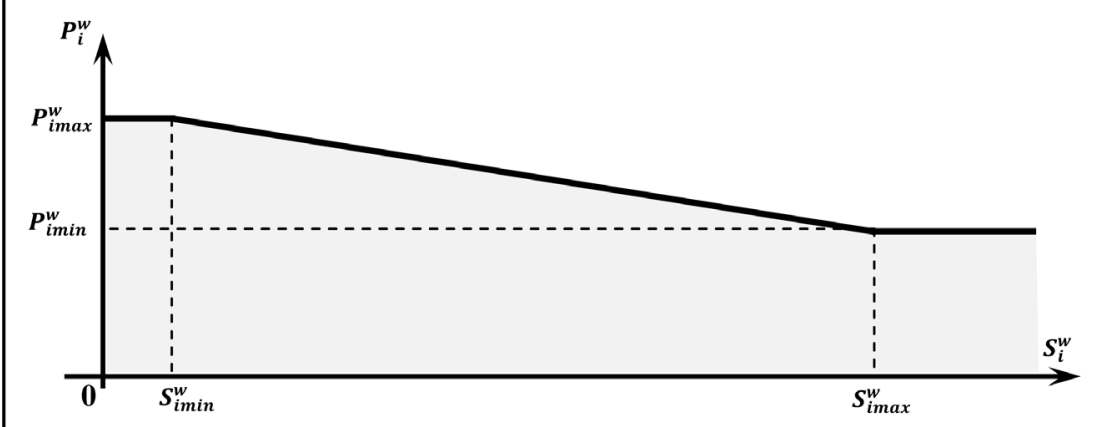

Figure 4. The proposed gradual cost of water resource $i$.

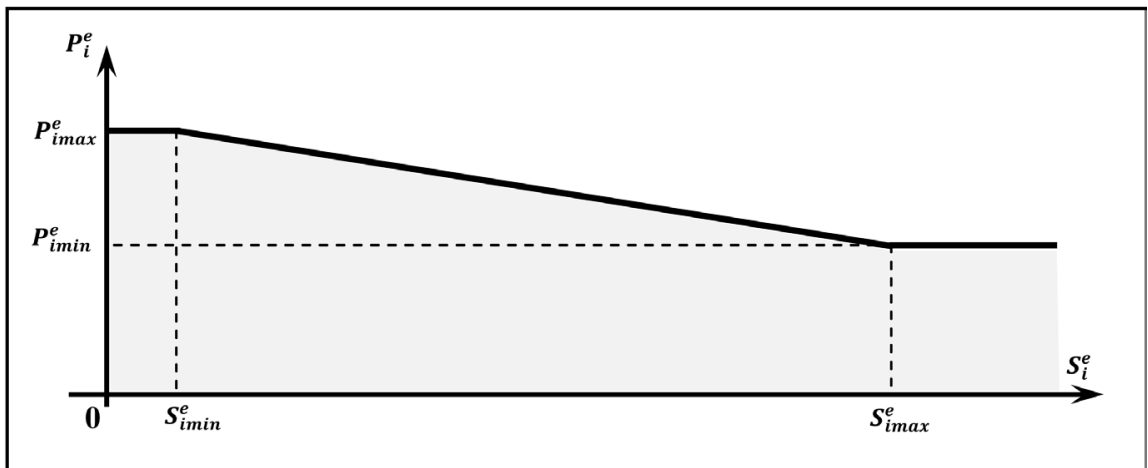

Figure 5. The proposed gradual cost of energy resource $i$. 
Similarly, if $\Delta z_{i}^{e}$ is the measure of the total additional intersectoral energy use (direct and indirect) of a resource $i$, the energy resource cost $\left(p_{i}^{e}\right)$ is calculated using the proposed method as follows:

$$
\begin{aligned}
& \text { If } \Delta z_{i}^{e}<S_{i \min }^{e} \text { then } p_{i}^{e}=P_{i \max }^{e} . \\
& \text { If } S_{i \min }^{e} \leq \Delta z_{i}^{e} \leq S_{i \max }^{e} \text { then } p_{i}^{e}=P_{i \min }^{e}+\left(S_{i \max }^{e}-\Delta z_{i}^{e}\right) \frac{P_{i \max }^{e}-P_{i \min }^{e}}{S_{i \max }^{e}-S_{i \min }^{e}} . \\
& \text { If } \Delta z_{i}^{e}>S_{i \max }^{e} \text { then } p_{i}^{e}=P_{i \min }^{e} .
\end{aligned}
$$

It is important to mention that the parameters $P_{i \min }^{w}, P_{i \max }^{w}, S_{i \min }^{w}, S_{i \max }^{w}$, $P_{i \min }^{e}, P_{i \max }^{e}, S_{i \min }^{e}$ and $S_{i \max }^{e}$ could differ between countries and across time to take into account national particular conditions and changes in cost due to changes in inflation and market fluctuations. Moreover, actual resources costs are affected by the specific technological and regional characteristics of a project, which involve numerous other factors not reflected in the assumed additional resource cost values. Nevertheless, in system performance optimization, assumed costs could be used as controlling objective in order to identify optimal performance solutions.

\section{Illustrative Example and Analysis of Results}

In order to put the developed framework in an application, a hypothetical case study of WEF nexus is presented. WEF nexus inflows that are considered are as follows:

Water inflows (including extraction, treatment, conveyance \& distribution) $\left(\mathrm{Mm}^{3} /\right.$ year): i) surface water ( $\left.W 1\right)$; ii) groundwater $(W 2)$; iii) desalination ( $\left.W 3\right)$; iv) wastewater reuse $(W 4)$; v) recycled water and agricultural drainage water reuse $(W 5)$.

Energy inflows (evaluated in terms of primary energy equivalent in ktoe/year on a net calorific value basis): i) imported petroleum (E1); ii) electricity (petroleum) (E2); iii) electricity (hydro) (E3); iv) imported electricity ( $E 4)$; v) electricity (wind/solar) (E5); vi) biofuels $(E 6)$.

Food inflows (including agriculture, food processing \& transportation) (kt/year): i) irrigated cereals $(F 1)$; ii) irrigated roots and tubers $(F 2)$; iii) irrigated vegetables (F3); iv) irrigated fruits (F4); v) Other Agriculture, Forestry \& Food products $(F 5)$.

Microsoft Excel provides a platform to build the WEF nexus simulator and it includes an optimizer (Frontline Excel Solver), so it is easy and direct coupling both simulator and optimizer without the need to construct a software coupling between an optimizer and the simulation tool. This will abstract both the WEF nexus simulation and the optimization problem into easily managed modules. The Q-Nexus Model is used for WEF nexus simulation and the Frontline Excel Solver [24] is used for optimization model. The Excel Solver is a suitable tool for this study since it is flexible and included with Microsoft Excel, nevertheless, any other optimizer could also be used.

Table 1 presents the WEF intersectoral use values $\left(z_{i j}^{w}{ }^{e}, z_{i j}^{w}-f, z_{i j}^{e}{ }^{w}, z_{i j}^{e}{ }^{e}\right.$, 
$\left.z_{i j}^{e-f}, z_{i j}^{f-e}, z_{i j}^{f-f}\right)$ and the corresponding end use values $\left(y_{i}^{w}, y_{i}^{e}, y_{i}^{f}\right)$. These values represent the Business As Usual (BAU) scenario. Biofuel production is not considered in this numerical experiment, the use of biomass was limited to end use for some economic activities or household use. Therefore, the food for energy indicators are not considered in this application.

The WEF intersectoral allocation coefficients $\left(c_{i j}^{w_{-} e}, C_{i j}^{w_{-} f}, C_{i j}^{e_{-} w}, c_{i j}^{e_{-} e}\right.$ and $\left.c_{i j}^{e^{-} f}\right)$ resulted from the BAU scenario are calculated using Equations (8)-(14) and results are presented in Table 2 . The total intersectoral water and energy use (direct and indirect) are $z^{w}=840.61 \mathrm{Mm}^{3}$ and $z^{e}=398.04$ ktoe, respectively.

Table 1. Intersectoral use of WEF inflows and the corresponding end use.

\begin{tabular}{|c|c|c|c|c|c|c|c|c|c|c|c|c|c|c|c|c|c|}
\hline & $W 1$ & $W 2$ & $W 3$ & $W 4$ & $W 5$ & $E 1$ & $E 2$ & $E 3$ & $E 4$ & $E 5$ & $E 6$ & $F 1$ & $F 2$ & $F 3$ & $F 4$ & $F 5$ & End Use \\
\hline$W 1$ & 0.00 & 0.00 & 0.00 & 0.00 & 0.00 & 0.00 & 16.66 & 0.00 & 0.00 & 0.00 & 0.00 & 85.13 & 60.45 & 79.46 & 114.15 & 257.57 & 64.0 \\
\hline$W 2$ & 0.00 & 0.00 & 0.00 & 0.00 & 0.00 & 0.00 & 0.00 & 0.00 & 0.00 & 0.00 & 0.00 & 26.79 & 23.50 & 32.47 & 55.76 & 79.27 & 320.0 \\
\hline$W 3$ & 0.00 & 0.00 & 0.00 & 0.00 & 0.00 & 0.00 & 0.00 & 0.00 & 0.00 & 0.00 & 0.00 & 0.00 & 0.00 & 0.00 & 0.00 & 0.00 & 30.0 \\
\hline$W 4$ & 0.00 & 0.00 & 0.00 & 0.00 & 0.00 & 0.00 & 1.00 & 0.00 & 0.00 & 0.00 & 0.00 & 0.24 & 0.18 & 0.24 & 0.30 & 0.54 & 0.0 \\
\hline$W 5$ & 0.00 & 0.00 & 0.00 & 0.00 & 0.00 & 0.00 & 0.00 & 0.00 & 0.00 & 0.00 & 0.00 & 1.34 & 1.01 & 1.34 & 1.68 & 1.52 & 7.0 \\
\hline$E 1$ & 2.87 & 4.39 & 0.03 & 0.21 & 0.22 & 0.00 & 0.00 & 0.00 & 0.00 & 0.00 & 0.00 & 12.13 & 4.54 & 6.95 & 10.77 & 20.42 & 1895.7 \\
\hline$E 2$ & 104.68 & 130.74 & 65.37 & 0.06 & 1.11 & 0.00 & 0.00 & 0.00 & 0.00 & 0.00 & 0.00 & 1.92 & 1.92 & 1.92 & 3.92 & 13.81 & 3095.9 \\
\hline$E 3$ & 1.35 & 1.43 & 1.55 & 0.00 & 0.09 & 0.00 & 0.00 & 0.00 & 0.00 & 0.00 & 0.00 & 0.01 & 0.01 & 0.01 & 0.88 & 0.04 & 99.7 \\
\hline$E 4$ & 0.39 & 0.47 & 0.46 & 0.00 & 0.04 & 0.00 & 0.00 & 0.00 & 0.00 & 0.00 & 0.00 & 0.01 & 0.01 & 0.01 & 0.88 & 0.04 & 40.5 \\
\hline$E 5$ & 0.00 & 0.00 & 0.00 & 0.00 & 0.00 & 0.00 & 0.00 & 0.00 & 0.00 & 0.00 & 0.00 & 0.00 & 0.00 & 0.00 & 0.00 & 2.35 & 5.1 \\
\hline$E 6$ & 0.00 & 0.00 & 0.00 & 0.00 & 0.00 & 0.00 & 0.00 & 0.00 & 0.00 & 0.00 & 0.00 & 0.00 & 0.00 & 0.00 & 0.00 & 0.00 & 26.0 \\
\hline$F 1$ & 0.00 & 0.00 & 0.00 & 0.00 & 0.00 & 0.00 & 0.00 & 0.00 & 0.00 & 0.00 & 0.00 & 0.00 & 0.00 & 0.00 & 0.00 & 7.00 & 144.0 \\
\hline$F 2$ & 0.00 & 0.00 & 0.00 & 0.00 & 0.00 & 0.00 & 0.00 & 0.00 & 0.00 & 0.00 & 0.00 & 0.00 & 0.00 & 0.00 & 0.00 & 0.00 & 352.0 \\
\hline$F 3$ & 0.00 & 0.00 & 0.00 & 0.00 & 0.00 & 0.00 & 0.00 & 0.00 & 0.00 & 0.00 & 0.00 & 0.00 & 0.00 & 0.00 & 0.00 & 2.00 & 854.0 \\
\hline$F 4$ & 0.00 & 0.00 & 0.00 & 0.00 & 0.00 & 0.00 & 0.00 & 0.00 & 0.00 & 0.00 & 0.00 & 0.00 & 0.00 & 0.00 & 0.00 & 0.00 & 508.0 \\
\hline$F 5$ & 0.00 & 0.00 & 0.00 & 0.00 & 0.00 & 0.00 & 0.00 & 0.00 & 0.00 & 0.00 & 60.87 & 0.00 & 0.00 & 0.00 & 0.00 & 7.00 & 3449.0 \\
\hline
\end{tabular}

Table 2. WEF intersectoral allocation coefficients of the BAU scenario.

\begin{tabular}{ccccccccccccccccccc}
\hline & $W 1$ & $W 2$ & $W 3$ & $W 4$ & $W 5$ & $E 1$ & $E 2$ & $E 3$ & $E 4$ & $E 5$ & $E 6$ & $F 1$ & $F 2$ & $F 3$ & $F 4$ & $F 5$ & 0.00 \\
$W 1$ & 0.00 & 0.00 & 0.00 & 0.00 & 0.00 & 0.00 & 1.00 & 0.00 & 0.00 & 0.00 & 0.00 & 0.52 & 0.52 & 0.52 & 0.59 & 0.54 \\
$W 2$ & 0.00 & 0.00 & 0.00 & 0.00 & 0.00 & 0.00 & 0.00 & 0.00 & 0.00 & 1.00 & 0.00 & 0.34 & 0.34 & 0.34 & 0.29 & 0.21 \\
$W 3$ & 0.00 & 0.00 & 0.00 & 0.00 & 0.00 & 0.00 & 0.00 & 0.00 & 0.00 & 0.00 & 0.00 & 0.00 & 0.00 & 0.00 & 0.00 & 0.00 \\
$W 4$ & 0.00 & 0.00 & 0.00 & 0.00 & 0.00 & 0.00 & 0.00 & 0.00 & 0.00 & 0.00 & 0.00 & 0.00 & 0.00 & 0.00 & 0.00 & 0.00 \\
$W 5$ & 0.00 & 0.00 & 0.00 & 0.00 & 0.00 & 0.00 & 0.00 & 0.00 & 0.00 & 0.00 & 0.00 & 0.13 & 0.13 & 0.13 & 0.11 & 0.25 \\
$E 1$ & 0.05 & 0.06 & 0.00 & 0.76 & 0.13 & 0.00 & 0.00 & 0.00 & 0.00 & 0.00 & 0.00 & 0.86 & 0.70 & 0.78 & 0.65 & 0.58 \\
$E 2$ & 0.93 & 0.92 & 0.97 & 0.23 & 0.84 & 0.00 & 0.00 & 0.00 & 0.00 & 0.00 & 0.00 & 0.14 & 0.30 & 0.22 & 0.24 & 0.42 \\
$E 3$ & 0.02 & 0.02 & 0.02 & 0.01 & 0.02 & 0.00 & 0.00 & 0.00 & 0.00 & 0.00 & 0.00 & 0.00 & 0.00 & 0.00 & 0.05 & 0.00 \\
$E 4$ & 0.01 & 0.01 & 0.01 & 0.00 & 0.01 & 0.00 & 0.00 & 0.00 & 0.00 & 0.00 & 0.00 & 0.00 & 0.00 & 0.00 & 0.05 & 0.00 \\
$E 5$ & 0.00 & 0.00 & 0.00 & 0.00 & 0.00 & 0.00 & 0.00 & 0.00 & 0.00 & 0.00 & 0.00 & 0.00 & 0.00 & 0.00 & 0.00 & 0.00 \\
$E 6$ & 0.00 & 0.00 & 0.00 & 0.00 & 0.00 & 0.00 & 0.00 & 0.00 & 0.00 & 0.00 & 0.00 & 0.00 & 0.00 & 0.00 & 0.00 & 0.00 \\
\hline
\end{tabular}


The estimated parameters of the cost of any projected additional water and energy resources $P_{i \min }^{w}, P_{i \max }^{w}, S_{i \min }^{w}, S_{i \max }^{w}, P_{i \min }^{e}, P_{i \max }^{e}, S_{i \min }^{e}$ and $S_{i \max }^{e}$ are shown in Table 3 and Table 4 . The surface water cost per meter cube is based on assuming constructing small rainwater harvesting reservoirs. It is important to mention that these estimated cost parameters should be adjusted based on the particular projects conditions of the water and energy plants.

A scenario of increasing the food products by $20 \%$ is considered. Based on the Q-Nexus Model simulator, and by assuming that the intersectoral intensities and allocation coefficients are unchanged, the total (direct and indirect) additional intersectoral quantities of water and energy are $\Delta z^{w}=163.57 \mathrm{Mm}^{3}$ and $\Delta z^{e}=46.72$ ktoe, respectively. The corresponding cost of the additional water and energy resources of the BAU scenario calculated using Equation (20) is 294.81 million USD.

By applying the proposed S-O framework, the best water and energy allocation coefficients that minimize the total provision cost of the additional water and energy resources will be calculated. The objective function (Equation (21)) and constraints (Equations (22)-(28)) will be considered. The maximum envisaged capacities of the additional water and energy resources inflows $v_{i}^{w}$ and $v_{i}^{e}$ are shown in Table 5 . The optimization tool will continually modifying the allocation coefficients while the WEF simulator will compute the corresponding direct and indirect intersectoral use. The resulted optimized allocation coefficients are presented in Table 6.

Table 3. Estimated cost parameters for additional water resources production.

\begin{tabular}{|c|c|c|c|c|c|}
\hline & $W 1$ & $w 2$ & $w 3$ & $W 4$ & W5 \\
\hline$P_{i \min }^{w}\left(\$ / \mathrm{m}^{3}\right)$ & 2.1 & 0.15 & 0.58 & 0.5 & 0.25 \\
\hline$P_{i \max }^{\mathrm{w}}\left(\$ / \mathrm{m}^{3}\right)$ & 5.4 & 0.45 & 1 & 0.81 & 0.85 \\
\hline$S_{i \min }^{w}\left(\mathrm{Mm}^{3}\right)$ & 10 & 5 & 1 & 2 & 2 \\
\hline$S_{i \max }^{w}\left(\mathrm{Mm}^{3}\right)$ & 100 & 50 & 10 & 20 & 20 \\
\hline
\end{tabular}

Table 4. Estimated cost parameters for additional energy resources production

\begin{tabular}{cccccccc}
\hline & & $E 1$ & $E 2$ & $E 3$ & $E 4$ & $E 5$ & $E 6$ \\
\hline$P_{i \min }^{e}$ & $(\$ /$ toe $)$ & 1 & 820 & 1800 & 150 & 1700 & NA \\
$P_{i \max }^{e}$ & $(\$ /$ toe $)$ & 2 & 1000 & 2200 & 200 & 2100 & NA \\
$S_{i \min }^{e}$ & $($ ktoe $)$ & 10 & 100 & 10 & 100 & 1 & NA \\
$S_{i \max }^{e}$ & $($ ktoe $)$ & 100 & 1000 & 100 & 1000 & 10 & NA \\
\hline
\end{tabular}

NA: Not Applicable

Table 5. Maximum capacity constraints of the additional water and energy resource inflows.

\begin{tabular}{ccccccccccc}
\hline \multicolumn{1}{c}{$\mathrm{Mm}^{3}$} & \multicolumn{1}{c}{ ktoe } \\
\hline$W 1$ & $W 2$ & $W 3$ & $W 4$ & $W 5$ & $E 1$ & $E 2$ & $E 3$ & $E 4$ & $E 5$ & $E 6$ \\
\hline 120.00 & 70.00 & 20.00 & 20.00 & 20.00 & 12.00 & 100.00 & 10.00 & 0.50 & 10.00 & 0.00 \\
\hline
\end{tabular}


Table 6. WEF intersectoral allocation coefficients that minimize the cost of the additional water and energy resources.

\begin{tabular}{ccccccccccccccccc}
\hline & $W 1$ & $W 2$ & $W 3$ & $W 4$ & $W 5$ & $E 1$ & $E 2$ & $E 3$ & $E 4$ & $E 5$ & $E 6$ & $F 1$ & $F 2$ & $F 3$ & $F 4$ & $F 5$ \\
\hline$W 1$ & 0.00 & 0.00 & 0.00 & 0.00 & 0.00 & 0.00 & 0.94 & 0.00 & 0.00 & 0.00 & 0.00 & 0.69 & 0.66 & 0.64 & 0.57 & 0.58 \\
$W 2$ & 0.00 & 0.00 & 0.00 & 0.00 & 0.00 & 0.00 & 0.00 & 0.00 & 0.00 & 1.00 & 0.00 & 0.28 & 0.31 & 0.33 & 0.39 & 0.36 \\
$W 3$ & 0.00 & 0.00 & 0.00 & 0.00 & 0.00 & 0.00 & 0.00 & 0.00 & 0.00 & 0.00 & 0.00 & 0.00 & 0.00 & 0.00 & 0.00 & 0.00 \\
$W 4$ & 0.00 & 0.00 & 0.00 & 0.00 & 0.00 & 0.00 & 0.06 & 0.00 & 0.00 & 0.00 & 0.00 & 0.00 & 0.00 & 0.00 & 0.00 & 0.00 \\
$W 5$ & 0.00 & 0.00 & 0.00 & 0.00 & 0.00 & 0.00 & 0.00 & 0.00 & 0.00 & 0.00 & 0.00 & 0.03 & 0.03 & 0.03 & 0.04 & 0.06 \\
$E 1$ & 0.01 & 0.04 & 0.00 & 0.76 & 0.15 & 0.00 & 0.00 & 0.00 & 0.00 & 0.00 & 0.00 & 0.86 & 0.70 & 0.78 & 0.67 & 0.59 \\
$E 2$ & 0.98 & 0.96 & 0.97 & 0.23 & 0.76 & 0.00 & 0.00 & 0.00 & 0.00 & 0.00 & 0.00 & 0.14 & 0.30 & 0.22 & 0.24 & 0.38 \\
$E 3$ & 0.00 & 0.00 & 0.02 & 0.00 & 0.06 & 0.00 & 0.00 & 0.00 & 0.00 & 0.00 & 0.00 & 0.00 & 0.00 & 0.00 & 0.04 & 0.00 \\
$E 4$ & 0.01 & 0.01 & 0.01 & 0.00 & 0.03 & 0.00 & 0.00 & 0.00 & 0.00 & 0.00 & 0.00 & 0.00 & 0.00 & 0.00 & 0.05 & 0.00 \\
$E 5$ & 0.00 & 0.00 & 0.00 & 0.00 & 0.00 & 0.00 & 0.00 & 0.00 & 0.00 & 0.00 & 0.00 & 0.00 & 0.00 & 0.00 & 0.00 & 0.03 \\
$E 6$ & 0.00 & 0.00 & 0.00 & 0.00 & 0.00 & 0.00 & 0.00 & 0.00 & 0.00 & 0.00 & 0.00 & 0.00 & 0.00 & 0.00 & 0.00 & 0.00
\end{tabular}

The cost of the additional water and energy resources of the optimized scenario is 259.09 million USD, which is $12 \%$ less than the cost calculated based on the allocation coefficients of the BAU scenario. The use of the proposed S-O framework allows policy maker to identify allocation coefficients from input parameters and to calculate direct and indirect intersectoral quantities by using the Q-Nexus Model to verify constraints and to minimize the objective cost function.

\section{Conclusions and Further Developments}

This study presents an effort to take advantage of the detailed evaluation capabilities of direct and indirect interactions of a WEF nexus simulation model within an optimization framework. The proposed approach shows that Q-Nexus Model can be used in a simulation-based analysis framework to allow for flexibility in choosing optimization tools, analyzing the impacts of model variables on WEF planning decisions, and considering a broad range of vital objective functions. Preliminary results from the proposed S-O framework show its ability to advance sustainable WEF sectors performance and resource use.

The proposed WEF nexus simulation and optimization framework will be used to guide policy making, where user could set any objective representing its own interest, given that WEF nexus simulator can provide the relevant outputs for objective function and constraints evaluation.

The Q-Nexus Model incorporates handling of multiple technological strategies that can also be considered in other management objectives. The extension of this work will be in the development and testing of relevant objective functions to represent the interest of WEF stakeholders, and will also include a comparison of multi-objective optimization approaches. These issues are still under development at our university. 


\section{References}

[1] Karnib, A. (2017) A Quantitative Assessment Framework for Water, Energy and Food Nexus. Computational Water, Energy, and Environmental Engineering, 6, 11 23. http://www.scirp.org/Journal/PaperInformation.aspx?PaperID=72359

[2] Technical University of Denmark (DTU) (2016) The Energy-Water-Food NexusFrom Local to Global Perspective. International Energy Report 2016, DTU Web. http://www.natlab.dtu.dk/english/energy_reports/dier_2016

[3] Hoff, H. (2011) Understanding the Nexus. Background Paper for the Bonn 2011 Conference: The Water, Energy and Food Security Nexus, Stockholm Environment Institute (SEI), Stockholm, Sweden.

[4] FAO (2013) An Innovative Accounting Framework for the Food-Energy-Water Nexus, Environment and Natural Resources Management. Working Paper No. 56, Food and Agriculture Organisation of the United Nations, Rome.

[5] FAO (2014) The Water-Energy-Food Nexus at FAO. Concept Note, Food and Agriculture Organisation of the United Nations, Rome.

[6] FAO (2014) Walking the Nexus Talk: Assessing the Water-Energy-Food Nexus in the Context of the Sustainable Energy for All Initiative. Food and Agriculture Organization of the United Nations, Rome.

[7] FAO (2014) The Water-Energy-Food Nexus-A New Approach in Support of Food Security and Sustainable Agriculture. Food and Agriculture Organization of the United Nations, Rome.

[8] Andrews-Speed, P., Bleischwitz, R., Boersma, T., Johnson, C., Kemp, G. and Van Deveer, S.D. (2012) The Global Resource Nexus: The Struggles for Land, Energy, Food, Water, and Minerals. Transatlantic Academy, Washington DC.

[9] Biggs, E.M., et al. (2015) Sustainable Development and the Water-Energy-Food Nexus: A Perspective on Livelihoods. Environmental Science \& Policy Journal, 54, 389-397.

[10] Boelee, E., Hoa, E. and Chiramba, T. (2014) UNEP's Engagement in the WaterEnergy-Food Nexus. Bonn 2014 Conference, Sustainability in the Water-EnergyFood Nexus.

[11] Waskom, R., Akhbari, M. and Grigg, N. (2014) U.S. Perspective on the WaterEnergy-Food Nexus. Completion Report No. 116, Colorado Water Institute.

[12] Bizikova, L., Roy, D., Swanson, D., Venema, H.D. and McCandless, M. (2013) The Water-Energy-Food Security Nexus: Towards a Practical Planning and DecisionSupport Framework for Landscape Investment and Risk Management. IISD Report, International Institute for Sustainable Development (IISD), Winnipeg, Canada. http://www.iisd.org/pdf/2013/wef_nexus_2013.pdf

[13] Fowler, K.R., Jenkins, E.W., Ostrove, C., Chrispell, J.C., Farthing, M.W. and Parno, M. (2015) A Decision Making Framework with MODFLOW-FMP2 via Optimization: Determining Trade-Offs in Crop Selection. Environmental Modelling \& Software, 69, 280-291.

[14] Thamaraiselvi A and Santhi R (2016) A New Approach for Optimization of Real Life Transportation Problem in Neutrosophic Environment. Mathematical Problems in Engineering, 2016, Article ID: 5950747.

[15] Pourhejazy, P. and Kwon, O.K. (2016) The New Generation of Operations Research Methods in Supply Chain Optimization: A Review. Sustainability, 8, 1033. https://doi.org/10.3390/su8101033

[16] Karnib, A. (2017) Evaluation of Technology Change Effects on Quantitative Assess- 
ment of Water, Energy and Food Nexus. Journal of Geoscience and Environment Protection, 5, 1-13.

http://www.scirp.org/Journal/PaperInformation.aspx?PaperID=74111

[17] Figueira, G. and Almada-Lobo, B. (2014) Hybrid Simulation-Optimization Methods: A Taxonomy and Discussion. Simulation Modelling Practice and Theory, 46, 118-134.

[18] Pan, S. and Ballot, E. (2015) Open Tracing Container Repositioning Simulation Optimization: A Case Study of FMCG Supply Chain. In: Borangiu, T., Thomas, A. and Trentesaux, D., Eds., Service Orientation in Holonic and Multi-Agent Manufacturing, Studies in Computational Intelligence Vol. 594, Springer International Publishing, Switzerland, 281-291.

[19] Sreekanth, J. and Datta, B. (2011) Coupled Simulation-Optimization Model for Coastal Aquifer Management Using Genetic Programming-Based Ensemble Surrogate Models and Multiple-Realization Optimization. Water Resources Research, 47, W04516. https://doi.org/10.1029/2010WR009683

[20] Zhen, L., Wang, K., Hu, H. and Chang, D. (2014) A Simulation Optimization Framework for Ambulance Deployment and Relocation Problems. Computers \& Industrial Engineering, 72, 12-23.

[21] Rani, D. and Moreira, M.M. (2010) Simulation-Optimization Modeling: A Survey and Potential Application in Reservoir Systems Operation. Water Resources Management, 24, 1107-1138. https://doi.org/10.1007/s11269-009-9488-0

[22] Zeng, Q. and Yang, Z. (2009) Integrating Simulation and Optimization to Schedule Loading Operations in Container Terminals. Computers \& Operations Research, 36, 1935-1944.

[23] EIA, U.S. Energy Information Administration (2016) Levelized Cost and Levelized Avoided Cost of New Generation Resources in the Annual Energy Outlook 2016. http://www.eia.gov/outlooks/aeo/pdf/electricity_generation.pdf

[24] Frontline Systems (2017) Excel Solver-Overview and Example. Frontline Systems, Inc. http://www.solver.com/excel-solver-overview-and-example

\section{Submit or recommend next manuscript to SCIRP and we will provide best service for you:}

Accepting pre-submission inquiries through Email, Facebook, LinkedIn, Twitter, etc. A wide selection of journals (inclusive of 9 subjects, more than 200 journals) Providing 24-hour high-quality service User-friendly online submission system Fair and swift peer-review system Efficient typesetting and proofreading procedure Display of the result of downloads and visits, as well as the number of cited articles Maximum dissemination of your research work

Submit your manuscript at: http://papersubmission.scirp.org/ Or contact gep@scirp.org 